\title{
Short- and Long-Time Improvement of Graft Function Using Iron-Chelator Supplemented Bretschneider Solution in a Canine Model of Orthotopic Heart Transplantation
}

\section{Gabor Szabo}

University of Halle (Saale)

Sivakkanan LOGANATHAN ( $\sim$ sivakkanan@gmail.com )

University of Halle (Saale)

Sevil KORKMAZ-ICÖZ

University of Heidelberg

Ágnes BALOGH

University of Debrecen

\section{Zoltan PAPP}

University of Debrecen

\section{Paige BRLECIC}

University of Heidelberg

\section{Péter HEGEDÜS}

University of Halle (Saale)

\section{Tamás RADOVITS}

Semmelweis University

\section{Matthias KARCK}

University of Heidelberg

\section{Béla MERKELEY}

University of Halle (Saale)

\section{Gabor Veres}

University of Halle (Saale)

\section{Research Article}

Keywords: organ demand, heart transplantation (HTX), Left ventricular (LV) , vasorelaxation experiments

Posted Date: August 18th, 2021

DOI: https://doi.org/10.21203/rs.3.rs-677187/v1 
License: (c) (i) This work is licensed under a Creative Commons Attribution 4.0 International License. Read Full License 


\section{Abstract}

An increasing organ demand is facing a constant number of donors. Nevertheless, not all organs are utilized due to a limited time window for heart transplantation (HTX). Therefore, we aimed to evaluate, if iron chelator supplemented Bretschneider solution can protect the graft in a clinically relevant canine model of HTX with prolonged ischemic storage.

HTX was performed in foxhounds. The ischemic time was standardized to $4 \mathrm{~h}, 8 \mathrm{~h}, 12 \mathrm{~h}$ or $16 \mathrm{~h}$ depending on the experimental group. Left ventricular (LV) and vascular function were measured. Additionally, myocardial high energy phosphate and iron content and in-vitro myocyte force were evaluated.

Iron chelator supplementation proved superior at a routine preservation time of $4 \mathrm{~h}$ as well as for prolonged times of $8 \mathrm{~h}$ and longer. The supplementation groups recovered quickly compared to their controls. The LV function was preserved and coronary blood flow increased. This was also confirmed by in vitro myocyte force and vasorelaxation experiments. Additionally, the biochemical results showed significantly higher adenosine-triphosphate content in supplementation groups. The iron chelator LK614 played an important role in this mechanism by reducing the chelatable iron content.

This study shows that iron chelator supplemented Bretschneider solution effectively prevents myocardial/endothelial damage during short as well as long term conservation.

\section{Introduction}

Heart transplantation (HTX) is the gold standard therapy for end-stage heart failure. Presently the oneyear survival rate of recipients is $90 \%{ }^{1,2}$ However, we are confronted with growing numbers of potential recipients and constant donor numbers, leading to an increasing organ deficit. ${ }^{1}$ In current literature various options have been suggested to solve this conflict. ${ }^{3}$ One approach is the reduction of unused potential donors by extending the maximum conservation time and thereby increasing the pool of suitable recipients.

A predominantly used cardioplegic, conservation solution in HTX is Custodiol (Bretschneider solution, HTK-solution), ${ }^{4,5}$ We believe that further development of this well-established solution may improve donor organ conservation. We have already previously described areas for improvement in the Custodiol solution. ${ }^{6-8}$ It is common knowledge that ischemia/reperfusion during cardiac surgery and transplantation causes myocardial and endothelial injury. ${ }^{9-11}$ It has also been shown that, paradoxically, the protective hypothermia used during routine cardiac surgery itself causes potentiated myocardial damage mostly via an increase in chelatable iron concentrations and the resulting formation of reactive oxygen species. ${ }^{12}$ Additionally, histidine - one main component used in Custodiol - has demonstrated cytotoxic effects. ${ }^{13}$ Taking this into account, a novel amino acid-fortified and iron chelator-supplemented Custodiol-based solution, Custodiol-N, was developed. (Table 1) In our previous studies, we first evaluated the effect of iron chelators and $\mathrm{N}$-alpha-acetyl-L-histidine on endothelial function after long-term, cold 
storage in vitro. We found that endothelial function was preserved by our improvements. ${ }^{8}$ Then, we studied Custodiol-N solution's capability in a rodent model of ischemia/reperfusion injury in the heart. Here we confirmed the superiority of Custodiol-N compared to Custodiol. ${ }^{7}$ Finally, Custodiol-N was tested in an animal model of cardiopulmonary bypass. Again, we showed that myocardial, as well as endothelial function, could be effectively preserved by Custodiol-N. ${ }^{6}$

Table 1

Compounds of Evaluated Cardioplegic Solutions

\begin{tabular}{|lll|}
\hline & $\begin{array}{l}\text { Custodiol } \\
(\mathbf{m m o l} / \mathbf{l})\end{array}$ & $\begin{array}{l}\text { Custodiol-N } \\
(\mathrm{mmol} / \mathrm{l})\end{array}$ \\
\hline $\mathrm{Na}^{+}$ & 15 & 16 \\
\hline $\mathrm{K}^{+}$ & 10 & 10 \\
\hline $\mathrm{Mg}^{2+}$ & 4 & 8 \\
\hline $\mathrm{Ca}^{2+}$ & 0.015 & 0.020 \\
\hline $\mathrm{Cl}^{-}$ & 50 & 30 \\
\hline L-Histidine & 198 & 124 \\
\hline $\mathrm{N}-\mathrm{a}-$-Acetyl-L-Histidine & - & 57 \\
\hline Tryptophan & 2 & 2 \\
\hline A-Ketoglutarat & 1 & 2 \\
\hline Aspartate & - & 5 \\
\hline Arginine & - & 3 \\
\hline Alanine & - & 5 \\
\hline Glycin & - & 10 \\
\hline Mannitol & - & - \\
\hline Sucrose & 30 & 0.025 \\
\hline Deferoxamine & - & 33 \\
\hline LK-614 & - & 5075 \\
\hline Composition of the clinically used Custodiol and the newly developed Custodiol-N solution \\
\hline
\end{tabular}

However, the evaluation of the Custodiol-N solution in clinically relevant large animal HTX model is still missing. In the present study we focused 1) on functional recovery in comparison to the standard HTKsolution, 2) on possible extension of safe conservation time and 3) elucidated some particular 
mechanism of actions of the novel solution which were not investigated in previous studies. Here special attention was paid on $\mathrm{Ca}^{2+}$-dependent force generation and iron homeostasis.

\section{Materials \& Methods}

\section{Animals}

Foxhounds (20-35kg; WOBE Ltd. Budapest, Hungary) were housed in a room at a constant temperature of $22 \pm 2^{\circ} \mathrm{C}$ with 12 -hour light/dark cycles and were fed a standard laboratory canine diet with water ad libitum. All animals received humane care in compliance with the "Principles of Laboratory Animal Care," formulated by the National Society for Medical Research, and with the "Guide for the Care and Use of Laboratory Animals" prepared by the Institute of Laboratory Animal Resources, published by the National Institutes of Health (NIH Publication No. 86-23, revised 1996). This study was approved by the appropriate institutional review committee (ethical committee of the University of Heidelberg, Medical Faculty, University of Heidelberg, Germany) and is reported in accordance with ARRIVE guidelines.

\section{Experimental Groups \& Study Design}

The study was subdivided into three series (Fig. 1):

In the first series standard cardiac preservation times (4h cold ischemic conservation) were utilized for an initial comparison of Custodiol and Custodiol-N. Baseline hemodynamic measurements, in vivo endothelial function and high energy phosphate content were compared.

In the second series longer conservation periods were evaluated. Hemodynamic measurements and coronary blood flow (CBF) were measured after 8,12 , and $16 \mathrm{~h}$ of ischemic conservation time. In the $8 \mathrm{~h}$ and $12 \mathrm{~h}$ groups we additionally examined histology and cardiomyocyte sensitivity to calcium. Based on the possibility to wean some animals from cardiopulmonary bypass in the $16 \mathrm{~h}$ group, we examined the in vitro endothelial function of both Custodiol, and Custodiol-N compared to native control hearts after $24 \mathrm{~h}$ conservation.

In the third series, the effectivity of the iron chelators LK-614 and deferoxamine, key components of Custodiol-N, were tested against Custodiol and native control hearts after $4 \mathrm{~h}$ and $12 \mathrm{~h}$ ischemic conservation.

\section{Orthotopic Heart Transplantation}

Cardioplegic arrest was induced using either Custodiol or Custodiol-N solution. Non-ischemic hearts served as controls. Donor hearts were preserved with the corresponding organ preservation solution for $4 \mathrm{~h}, 8 \mathrm{~h}, 12 \mathrm{~h}$ or $16 \mathrm{~h}$. Then, orthotopic HTX was performed followed by a $2 \mathrm{~h}$ reperfusion periode. For measurement of iron content in series 3 (Fig. 1) heart samples were taken after 10min of reperfusion.

\section{Hemodynamic measurements}


A Millar pressure-conductance catheter was used to measure pressure-volume relationships and calculate load independent indices of myocardial contractility. CBF was evaluated by an ultrasonic flow meter placed on the left anterior descending coronary artery of the donor heart.

In series 1 endothelial function was tested in vivo: Coronary endothelium-dependent and endotheliumindependent vasodilatation were assessed after administration of an intracoronary bolus of acetylcholine $\left(10^{-7} \mathrm{M}\right)$ or nitroglycerin $\left(10^{-4} \mathrm{M}\right)$, respectively.

\section{In vitro organ baths functional experiments}

Organ bath experiments were performed as previously described. ${ }^{14}$ Briefly, after removal of the recipient animals' hearts, the coronary arteries were isolated carefully, transversely cut into $4 \mathrm{~mm}$ wide rings, immersed in cold $\left(+4{ }^{\circ} \mathrm{C}\right.$ ) cardioplegic solution (Custodiol or Custodiol- $\mathrm{N}$ ) and stored for $24 \mathrm{~h}$ before evaluation. Coronary rings of the control group were immediately mounted in the organ bath without ischemic storage. Hypochlorite (200 $\mu \mathrm{M}, 30$ minutes), a highly reactive oxygen species was added to mimic the free radical burst, which usually occurs in vivo during reperfusion. In each vessel ring, endothelium-dependent (acetylcholine) and -independent (sodium nitroprusside) vasorelaxation were investigated.

\section{In vitro force measurements}

After mechanical isolation of myocardial tissue samples (original heart of recipient animals served as controls), permeabilization was performed with $0.5 \%$ Triton-X 100 detergent and a single cardiomyocyte was attached to two thin stainless-steel needles, which were connected to a force transducer (SensoNor, Horten, Norway) and to an electromagnetic motor (Aurora Scientific Inc., Aurora, Canada). Isometric force measurements were performed during repetitive activation-relaxation cycles at $15^{\circ} \mathrm{C}$, first at a sarcomere length (SL) of $1.9 \mu \mathrm{m}$ and then at a $\mathrm{SL}$ of $2.3 \mu \mathrm{m}$. $\mathrm{Ca}^{2+}$-contractures were evoked by transferring the myocyte from a $\mathrm{Ca}^{2+}$-free relaxing solution to activating solutions of gradually increasing $\mathrm{Ca}^{2+}$ concentrations. Active isometric and passive forces were normalized for cardiomyocyte cross-sectional area. Isometric force values were normalized for maximal $\mathrm{Ca}^{2+}$-activated active force. Then, $\mathrm{Ca}^{2+}$-force relations were plotted to determine the $\mathrm{Ca}^{2+}$-sensitivity of isometric force production, i.e. $\mathrm{pCa}_{50}$.

\section{Histology}

Myocardial tissue samples were taken from hearts conserved in Custodiol, Custodiol-N ( $8 \mathrm{~h}$ and $12 \mathrm{~h}$ ) as well as from native control hearts, fixed in buffered paraformaldehyde solution (4\%) and embedded in paraffin. Then, $5 \mu \mathrm{m}$-thick sections were stained with hematoxylin/eosin for histopathological evaluation.

\section{Determination of high energy phosphates}

The analysis was performed as described previously. ${ }^{6}$ Briefly, $1 \mathrm{~g}$ of heart tissue was homogenized in $10 \mathrm{ml} 3.5 \% \mathrm{HClO}_{4}$ and then centrifuged. Five $\mathrm{ml}$ supernatant was neutralized with $1 \mathrm{ml}$ triethanolamin$\mathrm{HCL} / \mathrm{K}_{2} \mathrm{CO}_{3}$ solution. Adenosine-triphospate (ATP) degradation was assessed with photometry using enzyme kinetic assay containing glycerinaldehyd-3-phosphate-dehydrogenase, 3-phosphoglycerat-kinase, 
glycerin-3-phosphat-dehydrogenase and triosephosphate-isomerase. Energy charge potential (ECP) was calculated as (ATP + 0.5ADP) / (ATP + ADP + AMP).

\section{Determination of total and chelatable iron concentrations}

To avoid a physiologically occurring quick normalization of iron concentations, samples were taken after 10 min reperfusion time. A new assay has been established for the determination of chelatable iron, detailed in the following:

PhenGreen calibration curve: physiological saline was incubated with Chelex 100 (Bio-Rad) (5g/100ml) overnight to chelate all free iron in the solution. Then PGSK (Life technologies, Darmstadt, Germany) was diluted to 15 different concentrations between 0 and $50 \mu \mathrm{M}$. Dilutions were spectrophotofluorometrically analyzed at $488 \mathrm{~nm}$ excitation and $505-530 \mathrm{~nm}$.

Sample measurements: $50 \mathrm{mg}$ heart tissue was suspended in the pretreated saline at $1 \mathrm{mg} / 10 \mu \mathrm{l}$ weight/volume ratio before homogenization and centrifugation. Supernant was taken and incubated with ascorbic acid and then with $50 \mu \mathrm{M}$ PhenGreen. Afterwards samples were analyzed at $488 \mathrm{~nm}$ excitation and 530nm emission.

\section{Statistics}

All data is expressed as the mean \pm standard error of the mean (SEM). Statistical analyses of data were performed using GraphPad Prism 7.02 software (GraphPad Sofware, Inc., CA, USA).

Series 1 \& 2: Individual means between the groups were compared by one-way analysis of variance followed by an unpaired t-test with Bonferroni correction for multiple comparisons. Regarding hemodynamic and CBF measurements the 8,12 and $16 \mathrm{~h}$ Custodiol-N groups were compared to baseline results using a paired t-test, as the animals in the Custodiol groups could not be weaned from cardiopulmonary bypass. A value of $p<0.05$ was considered statistically significant.

Series 3: ANOVA was used to compare the differences between the groups followed by the post-hoc Scheffe's test. A value of $p<0.05$ was considered statistically significant.

\section{Results}

\section{Series 1:}

\section{Hemodynamic measurements}

Hemodynamic variables did not significantly differ among the groups at baseline. After reperfusion, mean arterial pressure (MAP) was significantly decreased in Custodiol and Custodiol-N groups compared to baseline without any significant difference between the groups. But cardiac output (CO) was significantly lower in the Custodiol than in the Custodiol-N group (Table 2). Additionally, systolic cardiac 
function, in terms of ESPVR and PRSW, was significantly better preserved in the Custodiol-N group (Fig. 2).

Table 2

Hemodynamic variables before and $2 \mathrm{~h}$ after orthotopic transplantation (Series 1: $4 \mathrm{~h}$ conservation time)

\begin{tabular}{|lllll|}
\hline & donor baseline & & after Htx & \\
\hline & Custodiol & Custodiol-N & Custodiol & Custodiol-N \\
\hline HR [beats/min] & $119 \pm 8$ & $132 \pm 6$ & $110 \pm 12$ & $135 \pm 7$ \\
\hline MAP [mmHg] & $85 \pm 6$ & $90 \pm 4$ & $59 \pm 6^{\#}$ & $62 \pm 2^{\#}$ \\
\hline CBF [I/min] & $2.22 \pm 0.11$ & $2.53 \pm 0.44$ & $1.86 \pm 0.48$ & $2.84 \pm 0.32^{\star}$ \\
\hline LVSP [mmH] & $49 \pm 5$ & $50 \pm 9$ & $28 \pm 3^{\#}$ & $55 \pm 7^{*}$ \\
\hline LVEDP [mmHg] & $711 \pm 14$ & $107 \pm 5$ & $90 \pm 7^{\#}$ & $96 \pm 6^{*}$ \\
\hline
\end{tabular}

HTX indicates heart transplantation, HR heart rate, MAP mean aortic pressure, $\mathrm{CO}$ cardiac output, CBF coronary blood flow, LVSP left ventricular systolic pressure, values given as mean \pm SEM, ${ }^{\#} p<0.05$ vs. corresponding baseline, ${ }^{\star} p<0.05$ Custodiol-N vs Custodiol

\section{Coronary blood flow}

While CBF decreased significantly after transplantation compared to baseline in the Custodiol group, the Custodiol-N group did not show this difference. Noticeably also in direct comparison of both experimental groups CBF was significantly lowered in the Custodiol group (Table 2). Similar results were observed for endothelium dependent vasorelaxarion in response to acetylcholine: Endothelial function was significantly reduced compared to baseline in the Custodiol group while no adverse effects were seen in the Custodiol-N group (Fig. 3) Meanwhile, endothelium independent vasorelaxation in response to nitroglycerin showed no significant differences (Fig. 3).

\section{High energy phosphates}

ATP-levels as well as the ECP were significantly improved using Custodiol-N compared to the Custodiol group (Table 3). 
Table 3

High energy phosphates (Series 1: 4h conservation time)

\begin{tabular}{|c|c|c|c|c|}
\hline & \multicolumn{2}{|c|}{ before transplantation } & \multicolumn{2}{|c|}{ after transplantation } \\
\hline & Custodiol & Custodiol-N & Custodiol & Custodiol-N \\
\hline ATP $[\mu \mathrm{mol} / \mathrm{g} \mathrm{drw}]$ & $13.2 \pm 1.7$ & $14.4 \pm 0.7$ & $4.5 \pm 1.1^{\#}$ & $14.6 \pm 1.7^{\star}$ \\
\hline ADP [ [ $\mathrm{mol} / \mathrm{g} \mathrm{drw}]$ & $3.8 \pm 1.1$ & $5.3 \pm 0.6$ & $3.6 \pm 1.3$ & $3.8 \pm 0.7$ \\
\hline AMP [umol/g drw] & $1.9 \pm 0.4$ & $1.3 \pm 0.2$ & $2.9 \pm 1.4$ & $0.6 \pm 0.1$ \\
\hline ECP & $0.78 \pm 0.03$ & $0.81 \pm 0.03$ & $0.57 \pm 0.03^{\#}$ & $0.86 \pm 0.06^{\star}$ \\
\hline
\end{tabular}

\section{Series 2}

\section{Hemodynamic measurements}

Hemodynamic variables did not significantly differ among the groups at baseline.

After HTX, Custodiol groups showed macroscopic signs of severe ischemic injury and no satisfactory contractile function could be detected. Not a single could be weaned from heart-lung machine. Therefore, no hemodynamic measurement is available. However, in the Custodiol-N groups contractility was still preserved after $8 \mathrm{~h}$ and $12 \mathrm{~h}$ (Table 4 and Fig. 4). The animals were hemodynamically stable under inotropic support. Even after 16h cold ischemic conservation time 5 out of 9 animals could be weaned from the cardiopulmonary bypass. Two of the remaining four animals underwent massive coronary air embolism and were considered as technical failure. In two cases, the animals could not be weaned from cardiopulmonary bypass, without any evidence of technical failure. Heart rate, LV systolic pressure and $\mathrm{CO}$ did not significantly differ over the time in any of the Custodiol-N groups. We detected a slight decrease in MAP values in the $8 \mathrm{~h}$ group, which reached the level of statistical significance in the case of $12 \mathrm{~h}$ and $16 \mathrm{~h}$ conservation (Table 4). LV contractility in terms of endsystolic-pressure-volume-relationship (ESPVR) and preload-recruitable-stroke-work (PRSW) was preserved (Fig. 4). 
Table 4

Hemodynamic variables before and $2 \mathrm{~h}$ after orthotopic transplantation (Series 2: long conservation time)

\begin{tabular}{|c|c|c|c|c|c|c|}
\hline & \multicolumn{2}{|c|}{$\begin{array}{l}\text { 8h conservation } \\
\text { Custodiol-N }\end{array}$} & \multicolumn{2}{|c|}{$\begin{array}{l}\text { 12h conservation } \\
\text { Custodiol-N }\end{array}$} & \multicolumn{2}{|c|}{$\begin{array}{l}\text { 16h conservation } \\
\text { Custodiol-N }\end{array}$} \\
\hline & $\begin{array}{l}\text { donor } \\
\text { baseline }\end{array}$ & after $\mathrm{Htx}$ & $\begin{array}{l}\text { donor } \\
\text { baseline }\end{array}$ & $\begin{array}{l}\text { after } \\
\text { Htx }\end{array}$ & $\begin{array}{l}\text { donor } \\
\text { baseline }\end{array}$ & $\begin{array}{l}\text { after } \\
\mathrm{Htx}\end{array}$ \\
\hline $\begin{array}{l}\mathrm{HR} \\
\text { [beats/min] }\end{array}$ & $130 \pm 10$ & $149 \pm 15$ & $127 \pm 6$ & $\begin{array}{l}156 \pm \\
11\end{array}$ & $137 \pm 7$ & $146 \pm 8$ \\
\hline MAP [mmHg] & $74 \pm 4$ & $61 \pm 4$ & $76 \pm 6$ & $58 \pm 6^{*}$ & $86 \pm 6$ & $60 \pm 9 *$ \\
\hline $\begin{array}{l}\mathrm{CO} \\
{[1 / \mathrm{min}]}\end{array}$ & $2.4 \pm 0.2$ & $2.4 \pm 0.3$ & $2.4 \pm 0.3$ & $\begin{array}{l}2.2 \pm \\
0.6\end{array}$ & $1.5 \pm 0.1$ & $\begin{array}{l}1.6 \pm \\
0.4\end{array}$ \\
\hline $\mathrm{CBF}[\mathrm{ml} / \mathrm{min}]$ & $19.3 \pm 2.5$ & $\begin{array}{l}39.4 \pm \\
4.7^{\star}\end{array}$ & $21 \pm 3$ & $40 \pm 3^{*}$ & $35 \pm 6$ & $43 \pm 7$ \\
\hline LVSP [mmHg] & $92 \pm 4$ & $76 \pm 5$ & $94 \pm 5$ & $82 \pm 7$ & $94 \pm 6$ & $86 \pm 16$ \\
\hline $\begin{array}{l}\text { LVEDP } \\
\text { [mmHg] }\end{array}$ & $8 \pm 1$ & $24 \pm 4^{*}$ & $9 \pm 1$ & $22 \pm 5$ & $3.1 \pm 1.1$ & $17 \pm 4^{*}$ \\
\hline
\end{tabular}

\section{Coronary blood flow}

After $8 \mathrm{~h}$ and $12 \mathrm{~h}$ ischemic conservation with Custodiol-N, CBF was significantly increased during reperfusion compared to baseline. However, our results failed to show a significance in the $16 \mathrm{~h}$ group (Table 4).

\section{In vitro vascular function}

As a supplementary part of series 2 , with $24 \mathrm{~h}$ cold ischemic preservation time, in vitro endothelial function showed the following results: In the Custodiol group a marked impairment of coronary endothelial function was demonstrated by a reduced maximal relaxation of isolated coronary artery segments to acetylcholine and by a rightward shift of the concentration-response curve when compared with the native control group. Custodiol-N successfully prevented this ischemia/reperfusion induced endothelial impairment. Endothelium independent vasorelaxation was not altered (Fig. 5).

\section{In vitro force measurement}

In the Custodiol group, it was difficult to prepare isolated cardiomyocytes for force measurements after $12 \mathrm{~h}$ ischemic time, as most cells were in a state of ischemic contracture. At $1.9 \mu \mathrm{m}$ sarcomere length, the calcium-sensitivity of contractile filaments of cardiomyocytes was significantly lower in the Custodiol 
group after $12 \mathrm{~h}$ when compared to native controls. This reduction was reversed in the Custodiol-N group (Fig. 6).

\section{Histology}

Histopathological signs of severe ischemic damage (necrosis, myofibrillar fragmentation, cellular swelling and tissue edema) were observed in the LV myocardium of transplanted hearts stored for $8 \mathrm{~h}$ and $12 \mathrm{~h}$ in Custodiol, which were less pronounced in the Custodiol-N groups (Fig. 7).

\section{Series 3}

\section{Determination of chelatable iron concentrations}

Chelatable iron concentrations were significantly higher in the Custodiol group compared to the Custodiol-N group after $4 \mathrm{~h}$ as well as $12 \mathrm{~h}$ of ischemia. Even at $12 \mathrm{~h}$ Custodiol- $\mathrm{N}$ groups did not significantly differ from the native control hearts. However, hearts conserved in Custodiol for $12 \mathrm{~h}$ showed significantly higher levels than native control hearts. There was a tendency towards higher iron concentrations after $12 \mathrm{~h}$ of preservation in comparison to the values after $4 \mathrm{~h}$ of preservation for both groups, Custodiol as well as Custodiol-N (Fig. 8).

\section{Discussion}

Even though, the number of potential HTX recipients has increased by $50 \%$ since $2004^{15}$, the number of donors has remained almost unchanged. Nevertheless, donors are regularly excluded from heart donation because of the limited preservation time to reach a suitable recipient. ${ }^{1}$ Improving the utilization rate of grafts is therefore an important goal in transplant surgery.

Ex vivo perfusion systems are one of the strategies which have been developed as solution. Oxygenated blood is used to perfuse the graft and hereby to reduce graft damage. Besides isolated case reports describing a conservation time of $8 \mathrm{~h}$ [Heartbeat device ${ }^{16}$ ] to $10 \mathrm{~h}$ [OCS by TransMedics ${ }^{17}$ ], reliable clinically relevant studies are still missing. As limiting factor activated blood and the further release of metabolic agents from the graft lead to cardiac edema and inflammation as a sign of myocardial impairment. ${ }^{18}$ Additionally, in terms of practicability several issues must be considered: Present ex vivo perfusion systems require special equipment and training of surgeons and technicians, which results in considerably higher costs. Therefore, this organ procurement procedure may not be feasible for all hospitals.

Based on these limitations we aimed on an improvement strategy of the well-established Custodiol solution. ${ }^{4-6,19-22}$ The primary target of our work was to further reduce myocardial damage during standard conservation times of $4 \mathrm{~h}$ and secondary to point out an opportunity to safely reach prolonged organ preservation without the need of specialized staff or expensive equipment. 
Indeed, the comparison of Custodiol to Custodiol-N in a $4 \mathrm{~h}$ ischemia/reperfusion setup (series 1, figure 2 and 3) showed that also in routine cardiac surgery with ischemic times of $4 \mathrm{~h}$ and less Custodiol-N could have an implication, which is indicated by a significant improvement of load independent contractility parameters - such as ESPVR and PRSW (Figure 2). Remarkably, the contractility was recovered almost to baseline levels in this setup.

Also the secondary goal, which was to titrate the absolute borders of Custodiol-N, showed remarkable results: In series 2 , long ischemic times of $8 \mathrm{~h}, 12 \mathrm{~h}$ and $16 \mathrm{~h}$ were evaluated. All Custodiol groups had macroscopic signs of severe ischemic injury in series 2 . None of the animals could be weaned from cardiopulmonary bypass, not even under inotropic support. In contrast, almost all animals from the Custodiol-N group could be weaned from the heart lung machine and were hemodynamically stable under inotropic support.

Improved vascular function, and thereby improved CBF, can contribute to better cardiac performance and better graft outcome.(35) This improvement was already seen as secondary findings in series 1, and it was confirmed during extended ischemic conservation periods in series 2 . Again, to find the absolute limitations of Custodiol- $\mathrm{N}$ we investigated $24 \mathrm{~h}$ ischemic conservation time and found only a significant impairment in the Custodiol group but not in the Custodiol-N group.

Several mechanisms behind these protective effects of Custodiol-N have already been described by our previous studies: Some of the agents used in Custodiol have been replaced by further developed substances. One of these is histidine, which on one hand is an excellent buffer but on the other also contributes to cell toxicity. ${ }^{7}$ It was partly replaced by $\mathrm{N}$-a-acetyl-L-histidine, which shares similar capabilities but has a reduced cellular uptake. ${ }^{6,7,13,20}$ Furthermore the membrane stabilizing amino acids glycine and alanine have been added to Custodiol-N. 6,7,20,23 Beside these well described mechanisms we were able to explore and prove the key mechanisms of Custodiol-N:

It is known that myocardial dysfunction and impairment of force are directly linked to sarcomere function. ${ }^{24,25}$ Sarcomere function itself is dependent to its sensitivity to $\mathrm{Ca} 2+$, which again can be altered by hyper- or hypo-phosphorilation. This sensitive balance between proteinkinase $A$, which indirectly increases the phosphorylation of sacromeric proteins, and proteinkinase $C$, which has contrary effects, is influenced by ischemia/reperfusion injury. ${ }^{26}$ In consequence an in- as well as a de-creased Ca2+ sensitivity indicates a dysregulated phosphorylation of sacromeric proteins and hereby a severe damage to the myocardial tissue. Our in vitro measurements of myocardial sacromeres $\mathrm{Ca} 2+$ sensitivity, showed a significantly decrease compared to native controls.(Figure 6) Custodiol-N preserved this balanced complex system and thereby myocardial function.

Beside these known mechanistic insides, we now focused on the generation of reactive oxygen species (ROS) by the Fenton reaction as key mechanism. ${ }^{12,20}$ The Fenton reaction is boosted by chelatable iron. ${ }^{7,12}$ Two different types of iron chelators were introduced, deferoxamine and LK614 [1-(N-hydroxy-Nmethylcarbamide)-3,4-dimethoxybenzol], to address this topic. LK614 is smaller and more lipophilic than 
deferoxamine, which allows membrane permeability. $7,20,27$ Indeed, for the first time we proved a reduction of chelateable iron content in vivo using a exclusively developed assay.(Figure 8) Together with our previous work, in which we showed a significant reduction of myocardial apoptosis, ${ }^{7}$ the present results gives us an impression of the link between iron chelators, reduction of iron content and hereby also of apoptosis and finally preservation of myocardial function.

In the past, also other pharmacologic approaches have been made to improve pre-existing cardioplegic solutions for prolonged ischemic storages: Baxter and collegues demonstrated the conservation of rat hearts for $16 \mathrm{~h}$ using Wisconsin solution supplemented by nitroglycerine. ${ }^{28}$ Kevelaitis et al suggested the $\mathrm{Na}+/ \mathrm{H}+$ exchange inhibitor cariporide as well as the mitochondrial $\mathrm{K}_{\text {ATP }}$ channel ( mitoK $_{\text {ATP }}$ ) agonist diazoxide in a rat model as additive to Celsior solution for prolonged storage. ${ }^{29}$ Similar results were seen

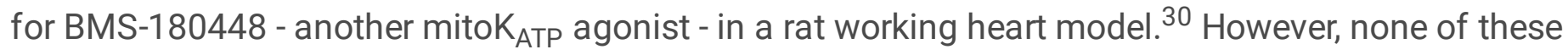
approaches could be advanced to a clinical trial. In contrast to that, our findings were conducted in this clinically relevant canine model and suggested a safety margin between $12 \mathrm{~h}$ and $16 \mathrm{~h}$. These results encouraged us to conduct a presently ongoing clinical trial using.

Summarizing, Custodiol-N has superior protection abilities compared to Custodiol at standard ischemic times. Unlike alternative approaches such as the ex vivo organ perfusion, Custodiol- $\mathrm{N}$ can be used very cost efficiently. Additionally, the results are promising for extended ischemic conservation periods. The mechanisms behind these effects are linked to a stabilization of $\mathrm{Ca}^{2+}$ sensitivity on sarcomere level and on the reduction of the chelateable iron pool. Therefore, our present approach for organ conservation may be an improvement in cardiac surgery.

\section{Limitations:}

The following limitations of this study must be addressed. To finally transfer these results to patients, additional, clinical studies must be performed. Additionally, further experimental are required to test the exact safety boundaries of Custodiol-N regarding extended ischemic conservation.

\section{Abbreviations}

$\mathrm{ACH}$ acetylcholine

ADP adenosine diphosphate

AMP adenosine monophosphate

ATP adenosine triphosphate

CBF coronary blood flow

CO cardiac output 
ECP energy charge potential

ESPVR endsystolic pressure volume relationship

HTK histidine tryptophane ketogluterate

HTX heart transplantation

LV left ventricular

MAP mean aterial pressure

mitoK $_{\text {ATP }}$ mitochondrial $\mathrm{K}_{\text {ATP }}$ channel

PRSW preload recruitable work

ROS reactive oxygen species

SEM standard error of the mean

SL sarcomere length

SNP sodium nitroprusside

\section{Declarations}

\section{Author Contribution:}

G Szabo, S Loganathan, S Korkmaz-Icöz and P Brlecic wrote the manuscript. G Szabo, A Balogh, Z Papp, $P$ Hegedüs, T Radovits, M Karck, B Merkeley and $G$ Veres contributed to the performing and analysis of the experiments. G Szabo and G Veres developed the study design. All authors revied the manuscript.

\section{Acknowledgements:}

The expert technical assistance of S. Schmack, A. Weymann, C. Miesel-Gröschel, S. Gügye and H. Bíró gratefully acknowledged.

\section{Conflict of Interest \& Funding:}

This study was supported by a grant from the National Development Agency of Hungary (TÁMOP) and by the Köhler Research Grant, Dr. Franz Köhler Chemie GmBH, Alsbach-Hähnlein, Germany.

The authors of this manuscript have no conflicts of interest to disclose as described by the American Journal of Transplantation 


\section{Data availability statement}

The data that support the findings of this study are available on request from the corresponding author.

\section{References}

1. Kittleson, M. M. Recent advances in heart transplantation. F1000Research, 7, https://doi.org/10.12688/f1000research.14737.1 (2018).

2. Lund, L. H. et al. The Registry of the International Society for Heart and Lung Transplantation: Thirtythird Adult Heart Transplantation Report-2016; Focus Theme: Primary Diagnostic Indications for Transplant. The Journal of heart and lung transplantation: the official publication of the International Society for Heart Transplantation, 35, 1158-1169 https://doi.org/10.1016/j.healun.2016.08.017 (2016).

3. Galeone, A. et al. A single-center long-term experience with marginal donor utilization for heart transplantation. Clin Transplant, e14057, doi:10.1111/ctr.14057 (2020).

4. Edelman, J. J. et al. Custodiol for myocardial protection and preservation: a systematic review. Ann Cardiothorac Surg, 2, 717-728 https://doi.org/10.3978/j.issn.2225-319X.2013.11.10 (2013).

5. Bretschneider, H. J. Myocardial protection. The Thoracic and cardiovascular surgeon, 28, 295-302 https://doi.org/10.1055/s-2007-1022099 (1980).

6. Veres, G. et al. -N, the novel cardioplegic solution reduces ischemia/reperfusion injury after cardiopulmonary bypass. Journal of cardiothoracic surgery, 10, 27 https://doi.org/10.1186/s13019015-0226-9 (2015).

7. Loganathan, S. et al. Effects of Custodiol-N, a novel organ preservation solution, on ischemia/reperfusion injury. The Journal of thoracic and cardiovascular surgery, 139, 1048-1056 https://doi.org/10.1016/j.jtcvs.2009.09.034 (2010).

8. Radovits, T. et al. Endothelial dysfunction after long-term cold storage in HTK organ preservation solutions: effects of iron chelators and N-alpha-acetyl-L-histidine. The Journal of heart and lung transplantation: the official publication of the International Society for Heart Transplantation, 27, 208-216 https://doi.org/10.1016/j.healun.2007.11.002 (2008).

9. Hearse, D. J. \& Bolli, R. Reperfusion induced injury: manifestations, mechanisms, and clinical relevance. Cardiovascular research, 26, 101-108 (1992).

10. Farb, A., Kolodgie, F. D., Jenkins, M. \& Virmani, R. Myocardial infarct extension during reperfusion after coronary artery occlusion: pathologic evidence. Journal of the American College of Cardiology, 21, 1245-1253 (1993).

11. Jernryd, V., Metzsch, C., Andersson, B. \& Nilsson, J. The influence of ischemia and reperfusion time on outcome in heart transplantation. Clin Transplant, 34, e13840 https://doi.org/10.1111/ctr.13840 (2020). 
12. Rauen, U., Petrat, F., Li, T. \& De Groot, H. Hypothermia injury/cold-induced apoptosis-evidence of an increase in chelatable iron causing oxidative injury in spite of low $02-/ \mathrm{H} 2 \mathrm{O} 2$ formation. FASEB journal: official publication of the Federation of American Societies for Experimental Biology, 14, 1953-1964 https://doi.org/10.1096/fj.00-0071com (2000).

13. Rauen, U., Klempt, S. \& de Groot, H. Histidine-induced injury to cultured liver cells, effects of histidine derivatives and of iron chelators. Cellular and molecular life sciences: CMLS, 64, 192-205 https://doi.org/10.1007/s00018-006-6456-1 (2007).

14. Radovits, T. et al. Poly(ADP-ribose) polymerase inhibition improves endothelial dysfunction induced by reactive oxidant hydrogen peroxide in vitro. European journal of pharmacology, 564, 158-166 https://doi.org/10.1016/j.ejphar.2007.02.060 (2007).

15. Colvin, M. et al. 2015 Annual Data Report: Heart. American journal of transplantation: official journal of the American Society of Transplantation and the American Society of Transplant Surgeons 17 Suppl 1, 286-356, doi:10.1111/ajt.14128 (2017).

16. Li, Y. et al. Development and Evaluation of Heartbeat: A Machine Perfusion Heart Preservation System. Artif Organs, 41, E240-E250 https://doi.org/10.1111/aor.12867 (2017).

17. Stamp, N. L. et al. Successful Heart Transplant after Ten Hours Out-of-body Time using the TransMedics Organ Care System. Heart, lung \& circulation, 24, 611-613 https://doi.org/10.1016/j.hlc.2015.01.005 (2015).

18. Cobert, M. L., West, L. M. \& Jessen, M. E. Machine perfusion for cardiac allograft preservation. Current opinion in organ transplantation, 13, 526-530 https://doi.org/10.1097/MOT.0b013e32830fdf9a (2008).

19. Prathanee, S., Kuptanond, C., Intanoo, W., Wongbhudha, C. \& Karunasumaeta, C. Custodial-HTK Solution for Myocardial Protection in CABG Patients. J Med Assoc Thai, 98 (Suppl 7), S164-167 (2015).

20. Kahn, J. \& Schemmer, P. Comprehensive Review on Custodiol-N (HTK-N) and its Molecular Side of Action for Organ Preservation. Curr Pharm Biotechnol, 18, 1237-1248 https://doi.org/10.2174/1389201019666180409165154 (2017).

21. Comai, S., Costa, C. V., Ragazzi, E., Bertazzo, A. \& Allegri, G. The effect of age on the enzyme activities of tryptophan metabolism along the kynurenine pathway in rats. Clinica chimica acta; international journal of clinical chemistry, 360, 67-80 https://doi.org/10.1016/j.cccn.2005.04.013 (2005).

22. Bretschneider, H. J. et al. Myocardial resistance and tolerance to ischemia: physiological and biochemical basis. The Journal of cardiovascular surgery, 16, 241-260 (1975).

23. Frank, A., Rauen, U. \& de Groot, H. Protection by glycine against hypoxic injury of rat hepatocytes: inhibition of ion fluxes through nonspecific leaks. Journal of hepatology, 32, 58-66 (2000).

24. Hamdani, N. et al. Sarcomeric dysfunction in heart failure. Cardiovasc Res, 77, 649-658 https://doi.org/10.1093/cvr/cvm079 (2008).

25. Ruppert, M. et al. Myofilament $\mathrm{Ca}(2+)$ sensitivity correlates with left ventricular contractility during the progression of pressure overload-induced left ventricular myocardial hypertrophy in rats. $J \mathrm{Mol}$ 
Cell Cardiol, 129, 208-218 https://doi.org/10.1016/j.yjmcc.2019.02.017 (2019).

26. Braz, J. C. et al. PKC-alpha regulates cardiac contractility and propensity toward heart failure. Nat Med, 10, 248-254 https://doi.org/10.1038/nm1000 (2004).

27. Wille, T., de Groot, H. \& Rauen, U. Improvement of the cold storage of blood vessels with a vascular preservation solution. Study in porcine aortic segments. Journal of vascular surgery, 47, 422-431 https://doi.org/10.1016/j.jvs.2007.09.048 (2008).

28. Baxter, K., Howden, B. O. \& Jablonski, P. Heart preservation with celsior solution improved by the addition of nitroglycerine., 71, 1380-1384 https://doi.org/10.1097/00007890-200105270-00004 (2001).

29. Kevelaitis, E., Oubenaissa, A., Mouas, C., Peynet, J. \& Menasche, P. Ischemic preconditioning with opening of mitochondrial adenosine triphosphate-sensitive potassium channels or $\mathrm{Na} / \mathrm{H}$ exchange inhibition: which is the best protective strategy for heart transplants? J Thorac Cardiovasc Surg, 121, 155-162 https://doi.org/10.1067/mtc.2001.111417 (2001).

30. Cropper, J. R., Hicks, M., Ryan, J. B. \& Macdonald, P. S. Enhanced cardioprotection of the rat heart during hypothermic storage with combined $\mathrm{Na}+-\mathrm{H}+$ exchange inhibition and ATP-dependent potassium channel activation. J Heart Lung Transplant, 22, 1245-1253 https://doi.org/10.1016/s1053-2498(03)00025-1 (2003).

\section{Figures}

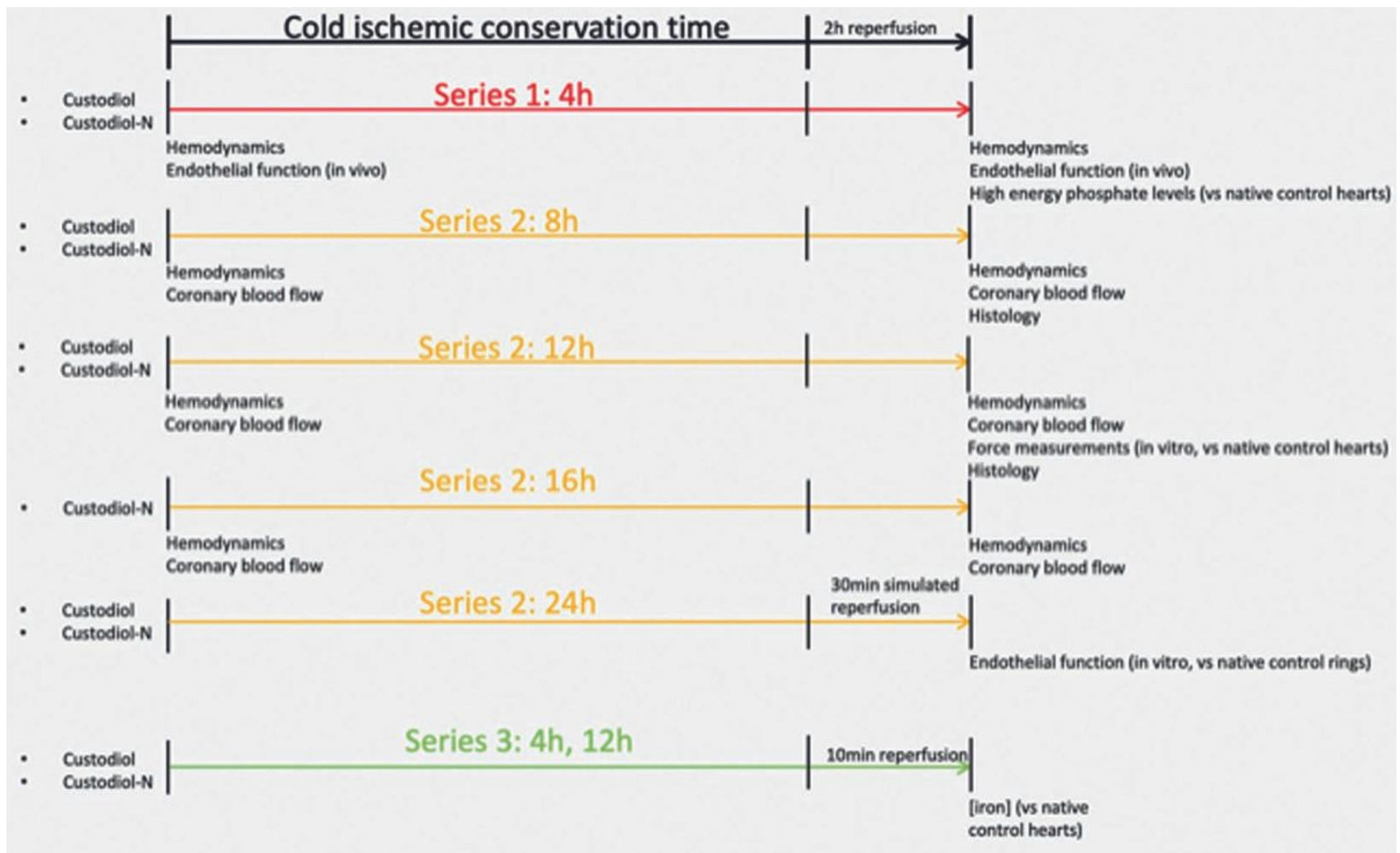


Figure 1

Study design
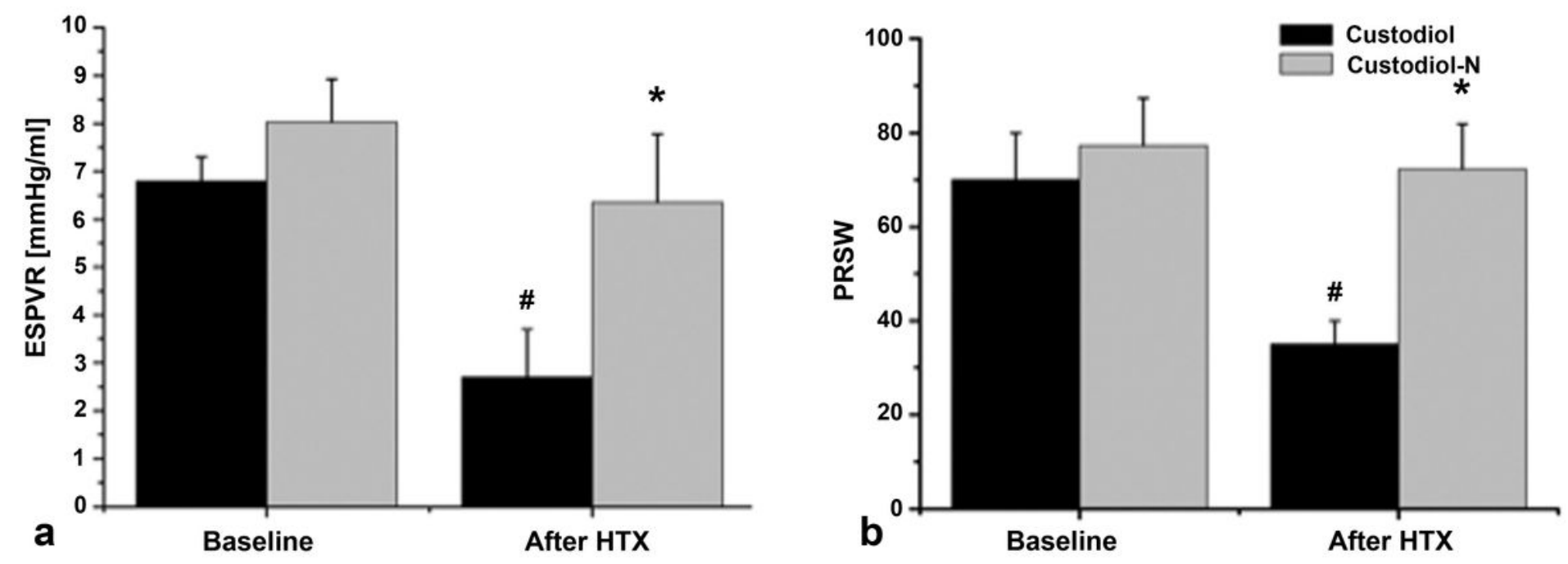

Figure 2

Hemodynamics (Series 1: 4h conservation time) A: End-systolic pressure-volume relationships (ESPVR); B: Preload recruitable stroke work (PRSW). Values given as mean $\pm S E M$. ${ }^{*} p<0.05$ vs. control, $\# p<0.05$ vs. corresponding baseline
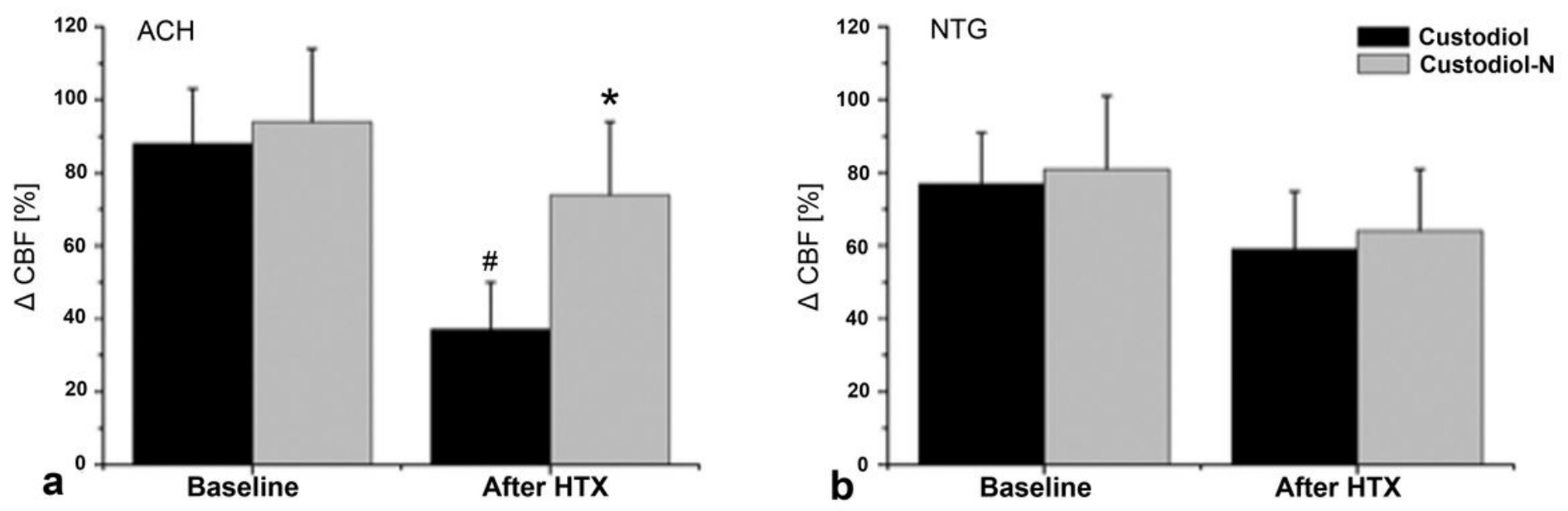

\section{Figure 3}

Coronary blood flow (Series 1: 4h conservation time) Percent change of coronary blood flow (CBF) after $A$ : acetylcholine $(\mathrm{ACH})$ or $B$ : nitroglycerin (NTG), respectively. Values given as mean $\pm S E M$. ${ }^{*} p<0.05$ vs. corresponding control, \#p<0.05 vs. corresponding baseline 

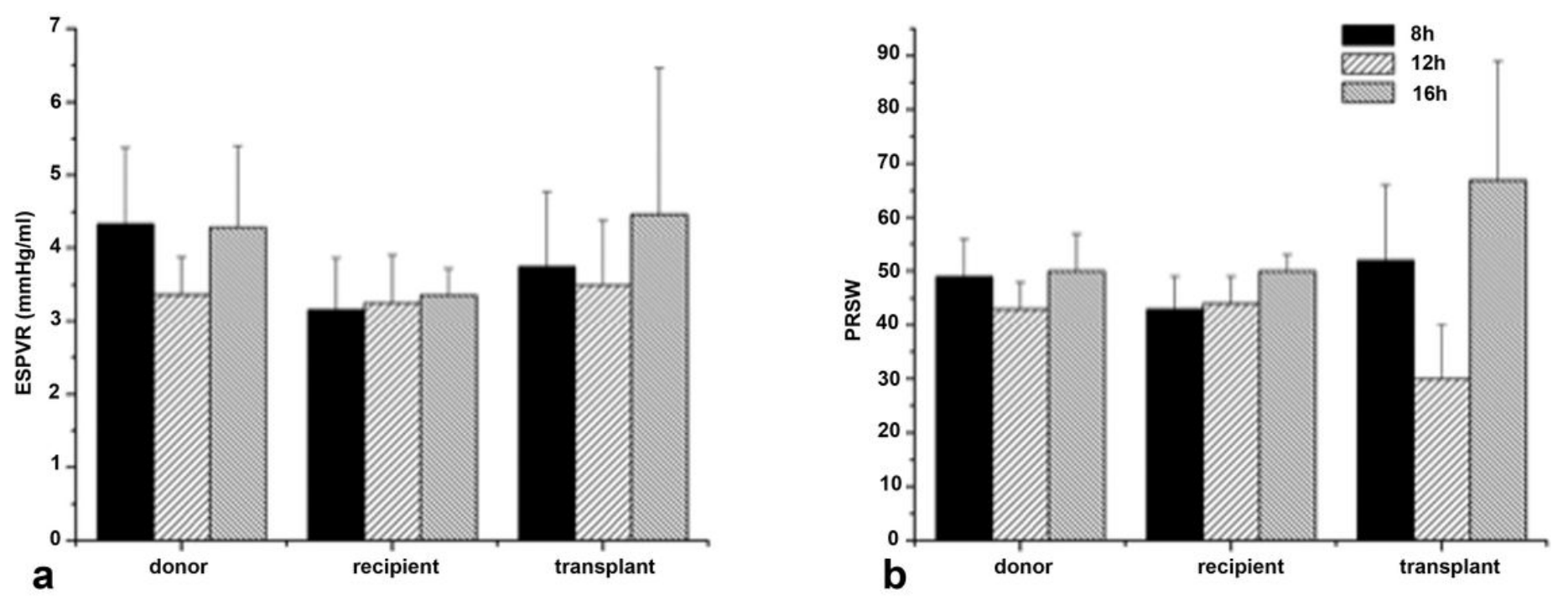

Figure 4

Hemodynamics (Series 2: long conservation time) A: End-systolic pressure-volume relationships (ESPVR); B: Preload recruitable stroke work (PRSW). Values given as mean $\pm S E M$. ${ }^{*} p<0.05$ vs. control, $\# p<0.05$ vs. corresponding baseline
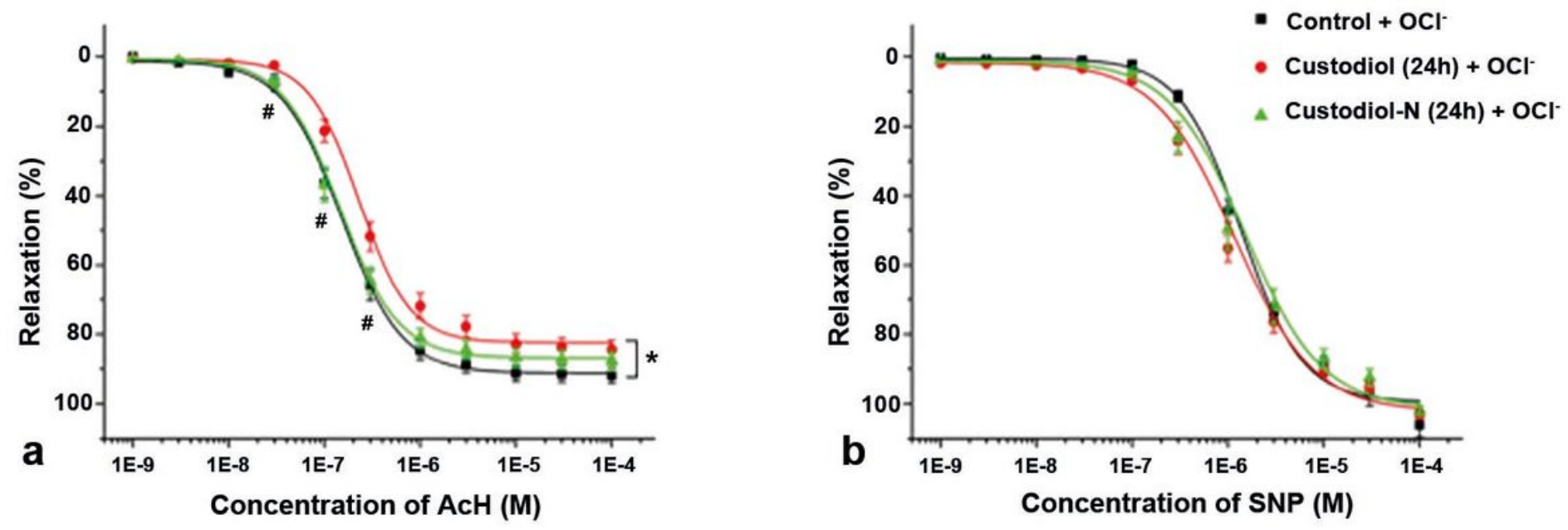

Figure 5

In vitro vascular function A: Acetylcholine (ACh)-induced, endothelium-dependent vasorelaxation of native control isolated coronary arterial segments and arteries that underwent cold ischemic conservation for 24h in Custodiol / Custodiol-N with addition of reactive oxidant hypochlorite ( $200 \mu \mathrm{mol} / \mathrm{liter})$. B: Sodium nitroprusside (SNP)-induced, endothelium-independent vasorelaxation of native control isolated coronary arterial segments and segments that underwent cold ischemic conservation for $24 \mathrm{~h}$ in Custodiol/Custodiol $\mathrm{N}$ with addition of reactive oxidant hypochlorite $(200 \mu \mathrm{mol} /$ liter). Each point of the curves represents the mean \pm SEM of $9-15$ experiments in the different groups. ${ }^{*} p<0.05$ vs. control, $\# p<0.05$ vs. Custodiol 


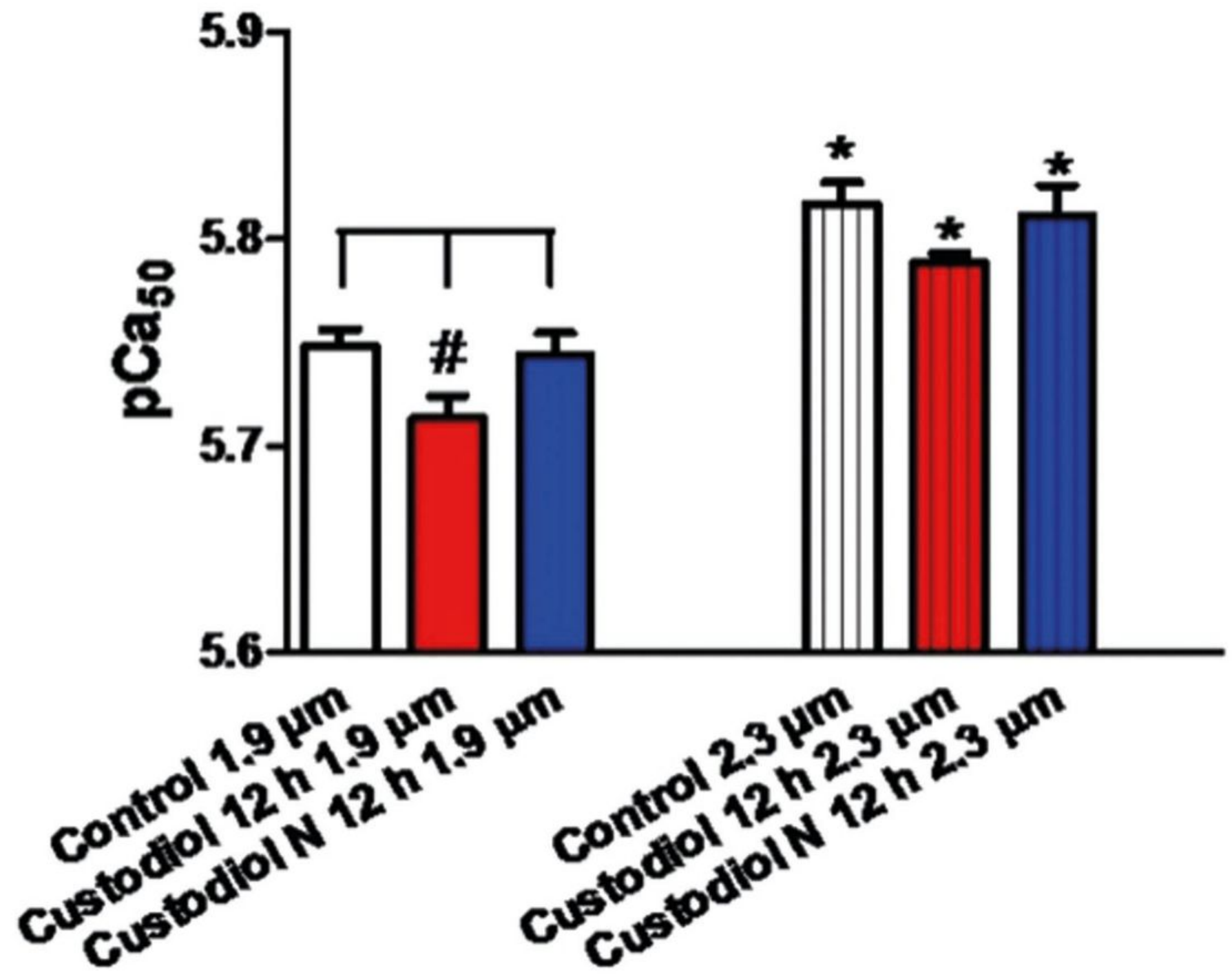

Figure 6

In vitro force measurements The calcium-sensitivity index pCa50 of isolated cardiomyocytes at 1.9 and $2.3 \mu \mathrm{m}$ sarcomere lengths from native control hearts and transplanted hearts of Custodiol and Custodiol$\mathrm{N}$ groups after $12 \mathrm{~h}$ ischemic conservation. Columns represent the mean \pm SEM of 5-17 experiments in the different groups. ${ }^{*} \mathrm{p}<0.05$ vs. $1.9 \mu \mathrm{m}, \# \mathrm{p}<0.05$ vs. as depicted 

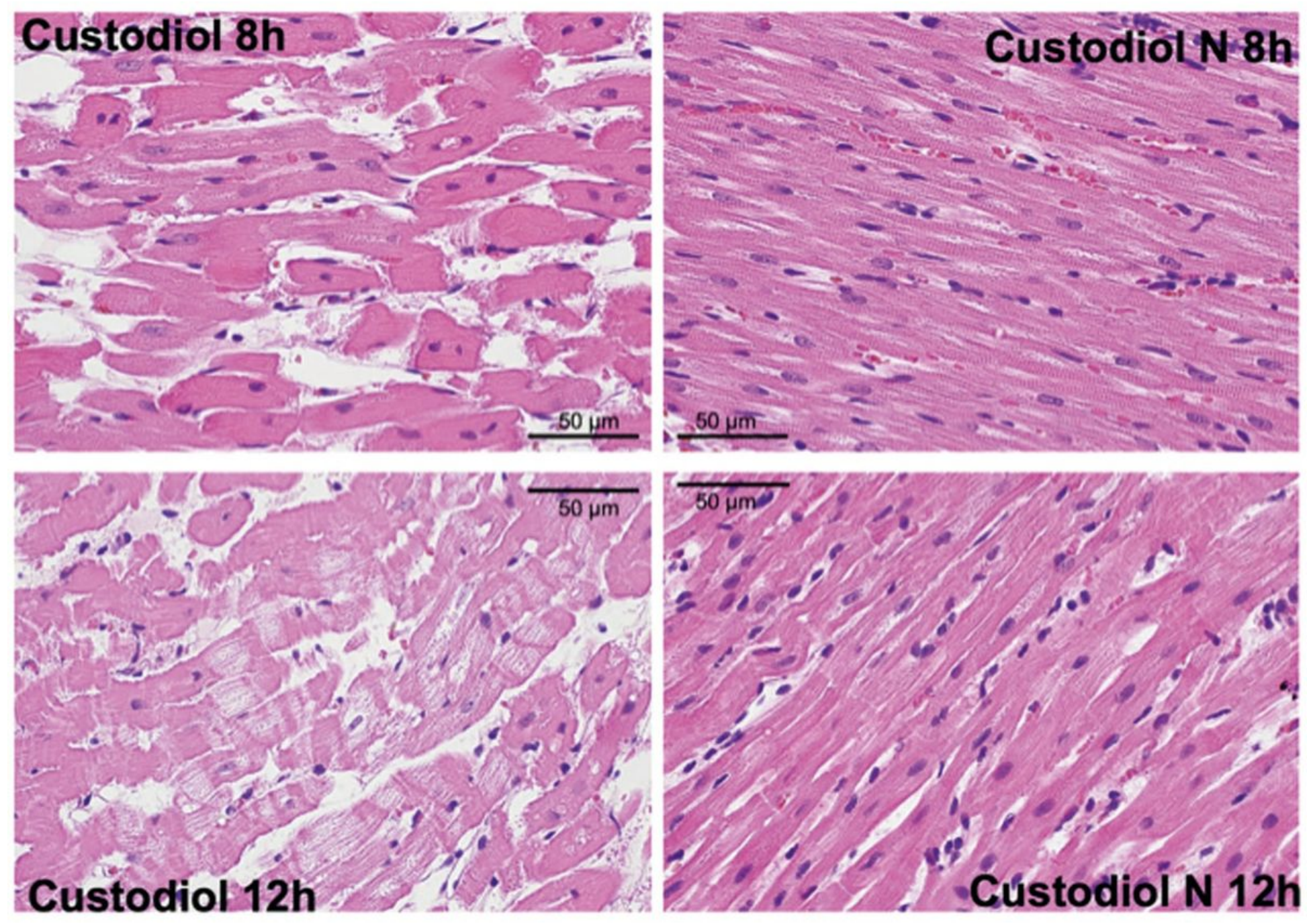

\section{Figure 7}

Histology Representative histopathological sections (haematoxylin-eosin staining) of the left ventricular myocardium of transplanted hearts in each experimental group. 


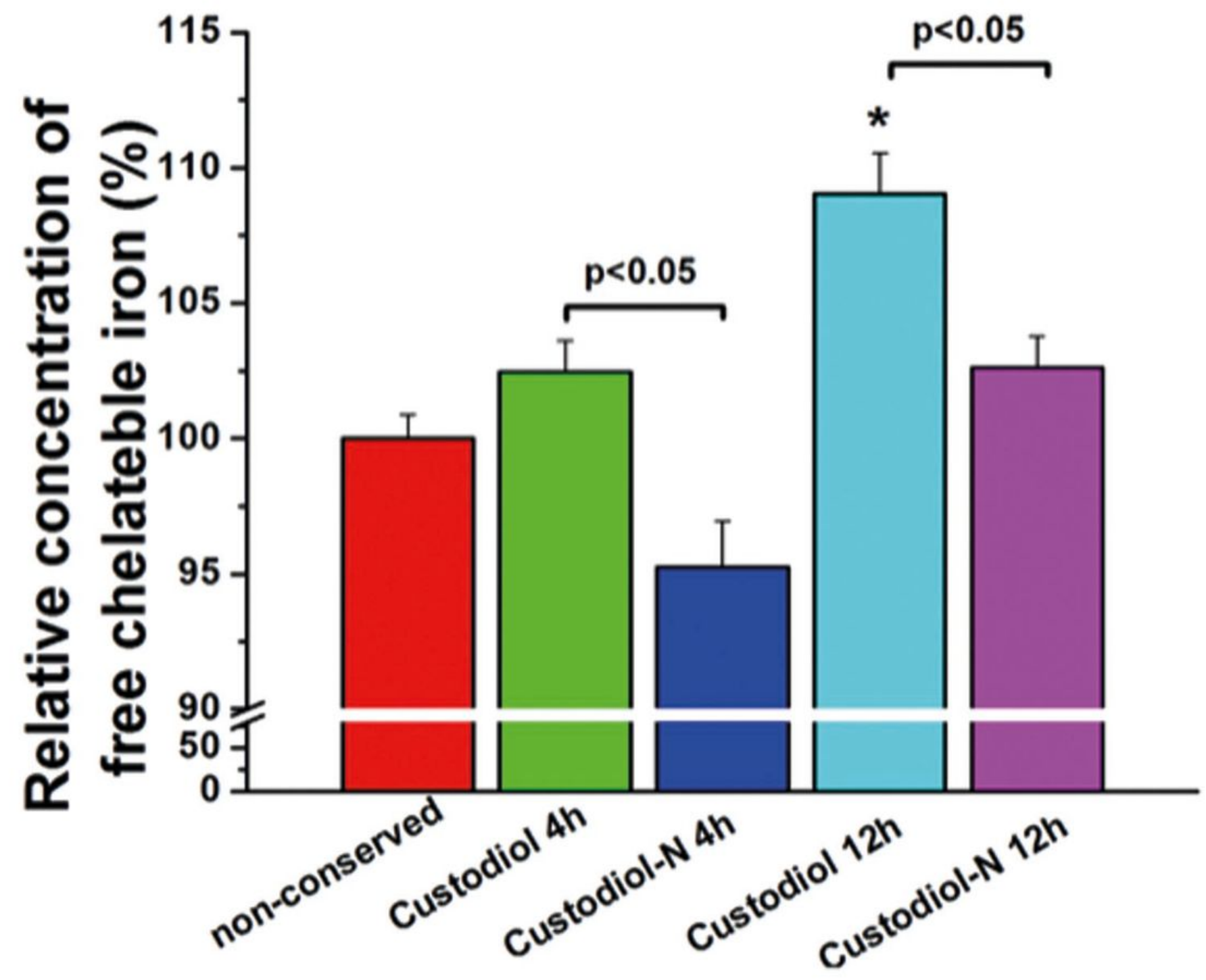

Figure 8

Chelatable iron concentration (Series 3) Chelatable iron concentrations are expressed as relative concentration normalized to native controls. values given as mean $\pm S E M, * p<0.05$ vs non-conserved 